\title{
Методы анализа редких и благородных металлов - пути развития
}

Ю. А. Карпов, д.х. Н., акад.РАН, В.Б. Барановская, д.х.Н., Институт общей и неорганической химии им. Н. С. Курнакова РАН, Москва baranovskaya@list.ru

"Аналитическая химия четко реагирует на запросы производства и черпает в этом силы и импульсы для дальнейшего развития..."

академик Н.С. Курнаков

В обзорной статье по материалам доклада на 76-х Курнаковских чтениях (декабрь 2018 года) описаны этапы развития методов аналитической химии редких и благородных металлов, начиная с середины 19 века. Показана эволюция физических методов анализа, в основе которых лежит теория измерения аналитического сигнала, строго специфичного для каждого химического элемента. За прошедшее столетие сформировались инструментальные методы неорганического анализа - атомно-спектральные, рентгеновские, масс-спектральные и радиоаналитические, которые в принципе пригодны для решения задач по анализу редких, редкоземельных, благородных металлов и материалов на их основе. Обсуждаются проблемы, значение и масштабы использования редких и благородных металлов в науке и производстве. Отмечен вклад выдающихся ученых 20 века - академиков Н. П. Сажина, Н. С. Курнакова, И. П. Алимарина и других в теорию химического анализа и изучения состава, строения и свойств редких и благородных металлов. Затронут вопрос становления новых методов аналитической нанодиагностики. Намечены пути и перспективы развития этого направления аналитической химии.

В 2019 году все международное сообщество отмечает 150 лет со дня открытия Д. И. Менделеевым Периодического закона и создания Периодической системы элементов, из которых состоит окружающий мир. Почти две трети всех элементов Периодической системы относятся к редким и благородным металлам.

История показывает, что кардинальные перемены в жизни человечества неразрывно связаны с появлением новых материалов. Эти перемены зафиксированы в названиях исторических эпох: каменный век, потом бронзовый, затем наступил век железный (табл. 1). С ускорением научнотехнического прогресса эти эпохи все быстрее сменяли друг друга. Наше время можно назвать веком новых материалов на основе редких, благородных металлов и высокочистых веществ. Это функциональные материалы, полупроводники, магнитные, оптические, лазерные материалы, сверхпроводники, жаропрочные вещества, катализаторы и т.д., которые востребованы в разных отраслях науки и техники, в том
«Физико-химический анализ является количественным измерением равновесных систем, которое дает возможность построить диаграмму состав - свойство и на основании последней делать выводы о взаимодействии между компонентами" Н. С. Курнаков 
числе атомной, полупроводниковой, электронной и др.

Фундаментальной основой науки о химических элементах и их соединениях является физико-химический анализ по Н.С. Курнакову, включающий исследование состава, строения и свойств изучаемых веществ и материалов.

Причем первичен в этой триаде химический состав, так как от него зависят структура и свойства. Проблеме определения состава и посвящена настоящая статья, первая часть которой касается анализа редких металлов, а вторая - благородных.

Единой классификации редких элементов не существует. Главным признаком редкого элемента считается распространенность в земной коре. В 1924 году американский ученый Дж. Д. Кларк установил представительный химический состав земной коры для глубины до 16 км (10 миль). Дальнейшие исследования советских ученых А. Е. Ферсмана и В.И. Вернадского, американцев Ч. Вашингтона, В.М.Гольдшмидта, ученых других стран подтвердили оценку Дж. Д. Кларка и дополнили ее сведениями об элементах, которые ранее не были известны. С тех пор принято называть кларком среднее процентное содержание любого элемента в земной коре. "Редкость" элемента зависит не только от малой распространенности в земной коре, а в большей степени от сложности и дороговизны технологии его производства и наличия соответствующих методов анализа. Академик Н. П. Сажин предложил следующую техническую классификацию редких металлов: легкие (Li,

\section{Курнаковские чтения"}

В Институте общей и неорганической химии им. Н. С. Курнакова РАН ежегодно в первых числах декабря проходят Курнаковские чтения, которые приурочены ко дню рождения основателя Института, академика Николая Семеновича Курнакова. Первые Чтения состоялись в 1942 году, во время Великой Отечественной войны, а в декабре 2018 года они прошли уже 76-й раз.

На Курнаковских чтениях выступают ведущие ученые, специалисты в различных областях неорганической, физической, аналитической, органической химии, кристаллохимии, геологии, материаловедения. Доклады посвящены важнейшим вопросам современного естествознания, проблемам внедрения достижений науки в производство. Курнаковские

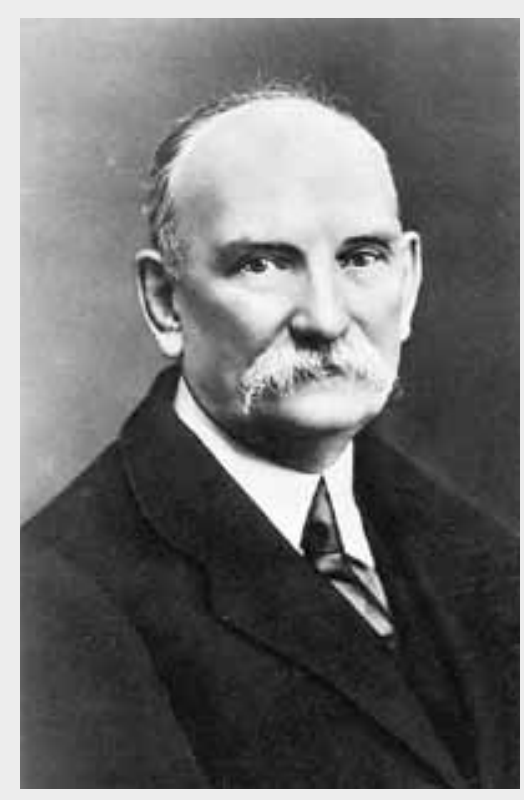

Академик Н. С. Курнаков 06.12.1860-19.03.1941

чтения - один из самых значимых научных химических форумов в России.

Информацию предоставил Ученый секретарь комиссии ИОНХ РАН по проведению Курнаковских чтений, д.х.н., профессор В.П. Данилов

Таблица 1. Элементы, известные человечеству в различные исторические эпохи

\begin{tabular}{|c|c|c|}
\hline Эпоха & Элементы & Число элементов \\
\hline Древние века & $\mathrm{N}, \mathrm{Al}, \mathrm{Fe}, \mathrm{Au}, \mathrm{K}, \mathrm{Ca}, \mathrm{O}, \mathrm{Si}, \mathrm{Cu}, \mathrm{Na}, \mathrm{Sn}, \mathrm{C}, \mathrm{Hg}, \mathrm{Pb}, \mathrm{Ag}, \mathrm{S}, \mathrm{Cl}, \mathrm{Zn}, \mathrm{Sb}$ & 19 \\
\hline До 18 века & Те же + As, Mg, Bi, Co, B, Ni, P & 26 \\
\hline 18 век & Те же + H, Pt, Ir, Y & 30 \\
\hline 19 век & Те же + Ba, Br, V, W, Cd, Mn, Mo, Os, Pd, Ra, Sr, Ta, F, Rh, U, Cr, Zr & 48 и некоторые Р3Э \\
\hline 20 век к 1915 году & Te же + Ne, Li, He, Ti, Ac, Ru, Rh & 55 и некоторые Р3Э \\
\hline 20 век к 1932 году & Te же + Be, Ar, Ga, Se, Rb, In, Y, Nb, Te, Hf, Re, TI, Cs & 48 и 14 Р3Э \\
\hline
\end{tabular}

$\mathrm{Rb}, \mathrm{Cs}, \mathrm{Be}) ;$ рассеянные (In, Ga, TI); редкоземельные (Sc, Y и все лантаниды); тугоплавкие (Ti, Zr, Hf, V, Nb, Ta, Mo, Re); радиоактивные (Ra и все актиниды). Редкие неметаллы (Ge, $\mathrm{Se}, \mathrm{Te})$ выделены в отдельную группу полупроводниковых элементов. Редкие металлы, расположенные в различных группах Периодической системы обладают поразительным разнообразием физических и химических свойств: например, 


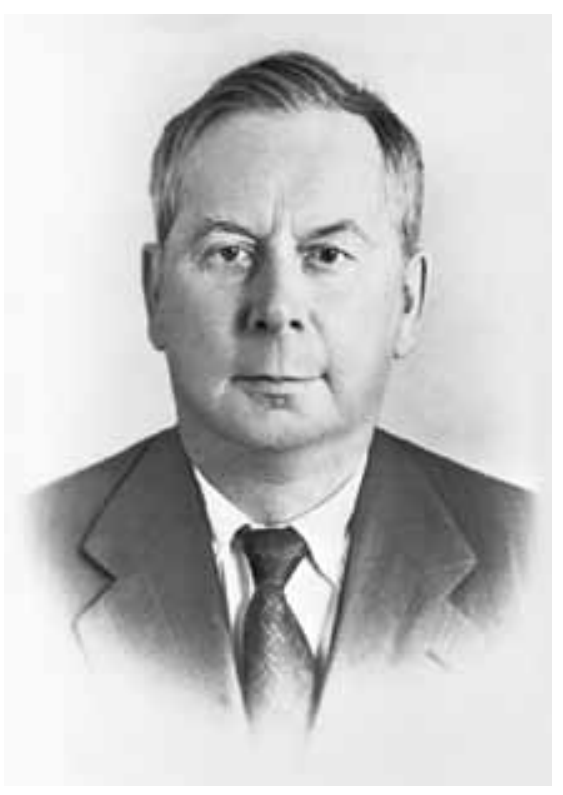

Академик

Н. П. Сажин 1897-1969

температуры плавления изменяются от $29^{\circ} \mathrm{C}$ - для галлия до $3400^{\circ} \mathrm{C}$ - для вольфрама.

В конце 19 века новым и дорогим (и потому редким) был алюминий, третий по распространенности элемент, только потому, что его не умели получать в промышленном масштабе в чистом виде. Д.И. Менделеев получил в подарок от Лондонского химического общества в 1889 году драгоцен- ные вазы и кубок из алюминия и золота. Тогда эти металлы были одинаково дорогими.

Специфические свойства редких металлов проявляются только при достижении высокого уровня их химической чистоты. Наглядным примером того, как новые иногда неожиданные свойства обнаруживаются у редких металлов с повышением их чистоты, могут служить титан, ниобий и цирконий. Долгое время эти металлы считались очень хрупкими, и только тщательная очистка от газовых примесей (кислорода, азота и водорода) выявила их удивительную пластичность и соответственно возможности широкого практического применения. Для этого был разработан метод их аналитического определения (высокотемпературная газовая экстракция), который до 60-х годов прошлого столетия применялся только для анализа сталей.

К началу 19 века было известно только 30 химических элементов. Среди них редких элементов не было, но были некоторые благородные - золото, серебро, платина и иридий. Такая ситуация в значительной мере объясняется недостаточными возможностями аналитической химии, методы которой на тот момент не позволяли идентифицировать новые элементы, отличать их от химических аналогов и сопутствующих веществ. Дело в том, что до 19 века аналитики пользовались только химическими методами анализа, которые не обладали необходимыми возможностями для селективной идентификации различных элементов, осо-

Возникновение в 30-х годах 20 века новых отраслей промышленности (редкометаллической, авиационной, нефтехимической)

- Становление металлургической отрасли редких металлов в 50-х годах 20 века

Определение низких концентраций РМ в присутствии высоких концентраций распространенных элементов
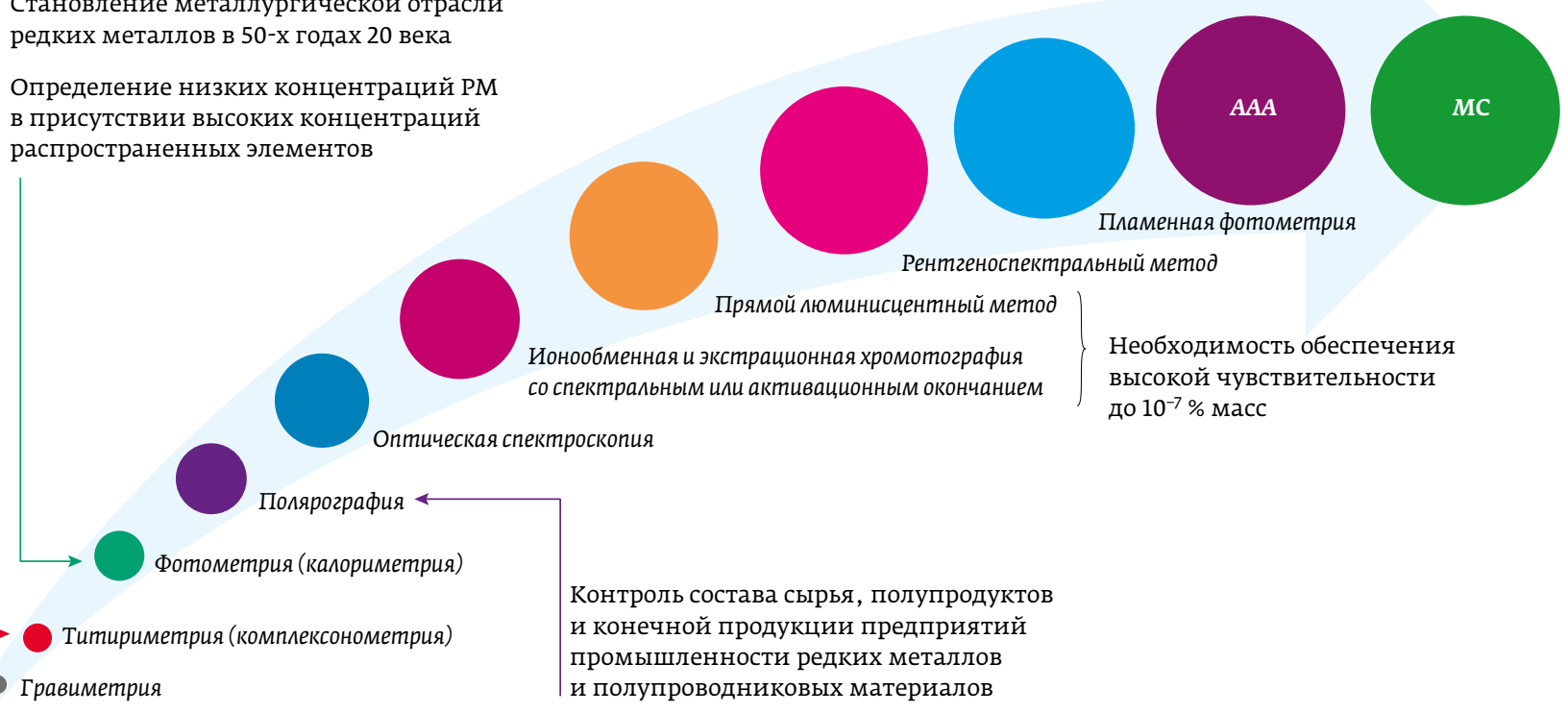

Ионообменная и экстрационная хромотография со спектрапьным или активационным окончанием

Необходимость обеспечения высокой чувствительности до $10^{-7} \%$ масс

Контроль состава сырья, полупродуктов и конечной продукции предприятий промышленности редких металлов и полупроводниковых материалов 


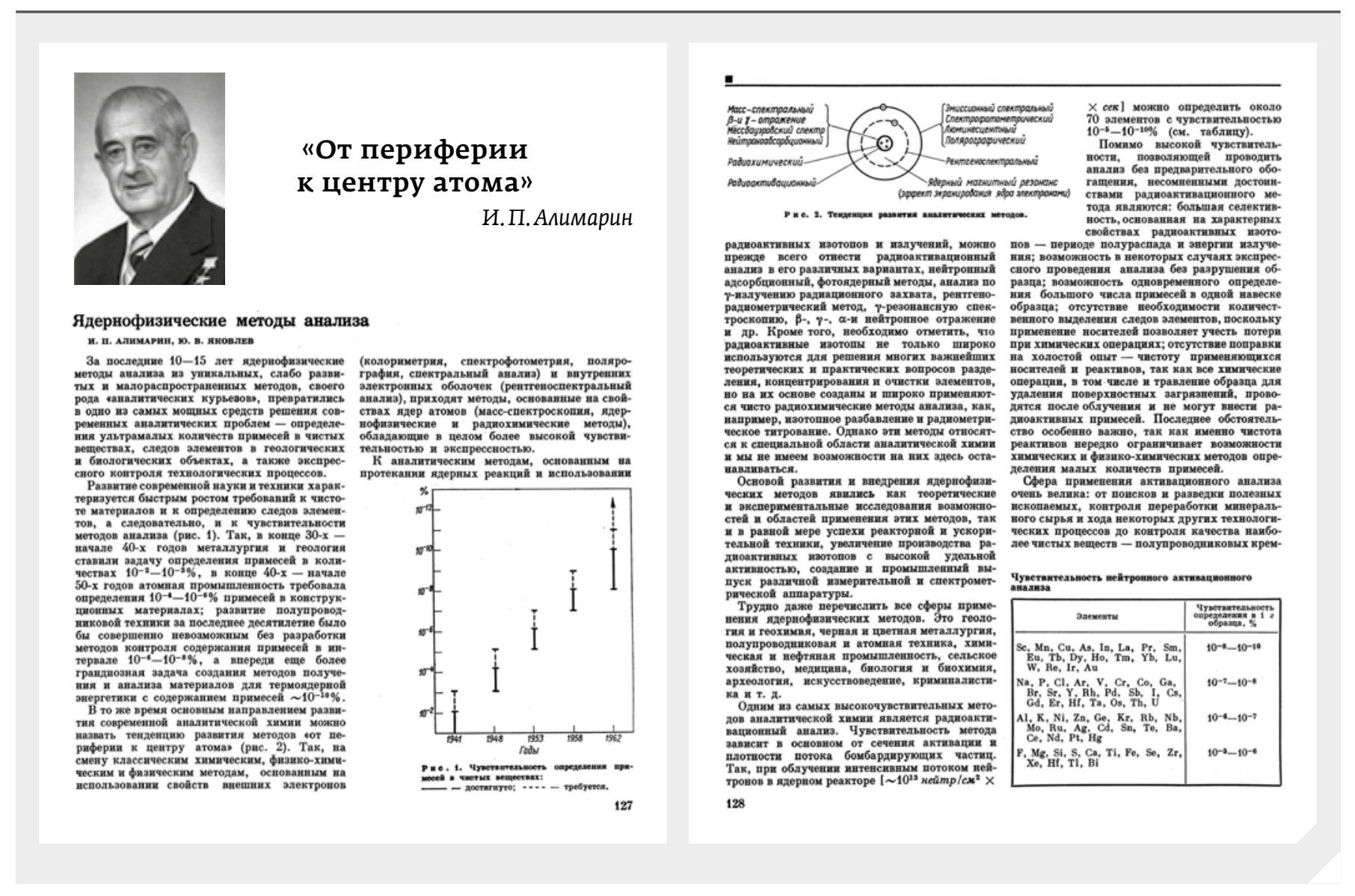

бенно при их низких содержаниях и на фоне других аналитов в составе анализируемых образцов. Остальные элементы открыты в 19-м и 20-м веках благодаря новым технологиям и научным достижениям, а также созданию целого комплекса физических методов анализа.

В основе физических методов анализа лежит теория аналитического сигнала, строго специфичного для каждого элемента, такого как отпечатки пальцев для каждого человека. Сущность любого метода анализа состоит в том, что на исследуемый образец оказывается некоторое внешнее воздействие, которое вызывает соответствующий отклик, называемый аналитическим сигналом. Этот сигнал отделяется от возможных помех и затем подвергается идентификации и измерению. Спектр применяемых методов воздействия очень широк: высокие температуры, различные виды излучения в широком диапазоне частот (оптическое, рентгеновское и др.), бомбардировка элементарными частицами, магнитное поле и многие другие.

Разные способы воздействия затрагивают различные части строения искомого атома - наружные электронные оболочки (атомно-спектральный анализ), средние электронные оболочки - рентгеновский анализ, нижние электронные оболочки (масс-спектрометрия) и, наконец, ядро (яМР и др.). В таком же порядке, который академик И. П. Алимарин назвал тенденцией "от периферии к центру атома", исторически развивались и физические методы. Такая последовательность связана не только с развитием науки, но и с возможностью создания совершенных аналитических приборов.

Родоначальники атомно-эмиссионной спектроскопии (часто называемой спектральным анализом) - немецкие ученые: физик Г. Кирхгоф и химик Р. В. Бунзен, а датой появления спектрального анализа считается 1860 год.

Спектральный анализ был воспринят, как революционное явление в аналитической химии. Сначала казалось, что этот метод заменит все остальные по своим универсальным возможностям. Однако по мере детального изучения, как это обычно бывает в любой науке, обнаружились его ограничения, связанные с использованием высоких температур, несовершенством оптики, влиянием состава вещества на результаты анализа, недостатками детекторов излучения, наложениями спектральных линий и другие. Поэтому романтическое утверждение поэта Арсения Тарковского «Был язык мой правдив как спектральный анализ" оказалось под сомнением. В результате до конца 19 века спектральный анализ оставался, в основном, методом качественного анализа, что тоже было немаловажно.

Со временем совершенствовались способы возбуждения спектра (дуга, искра, пламя, плазма), разрабатывались приборы с современной оптикой, высокоэффективные много- 
канальные детекторы. Спектральный анализ постепенно перешел в разряд основных методов исследования веществ и материалов на основе редких и редкоземельных металлов, поскольку с его помощью можно выполнять многоэлементный анализ и различать элементы с близкими химическими свойствами (например, редкоземельные).

В 1955 году 20 века появился еще один атомно-спектральный метод - атомно-абсорбционная спектрометрия (ААC), который благодаря своей простоте и большим возможностям стал широко востребованным. Сам метод изобрел в 1953 году австралийский профессор Алан Уолш, он же стал создателем спектрометра с пламенным атомизатором, а электротермический вариант атомизации в графитовой печи предложил профессор из Ленинграда Б. В. Львов.

В начале 20 века английский ученый Г. Мозли впервые определил концентрацию редкоземельных элементов в их смеси методом рентгеновского анализа. Развитый затем в ряде модификаций этот метод сегодня по-прежнему остается одним из наиболее важных и распространенных в анализе редких и благородных металлов.

Следующая в списке основных методов неорганического анализа - масс-спектрометрия. Главный параметр, определяемый с ее помощью - отношение массы иона к его заряду, которое с высокой точностью позволяет определять состав исследуемого образца. Метод нашел универсальные применения в анализе смесей редких элементов, их изотопов, высокочистых веществ. Он продолжает развиваться и, возможно, в ближайшие годы станет самым перспективным в аналитической химии редких и благородных металлов.

И, наконец, заключительная часть пути "от периферии к центру атома" - радиоаналитические методы. Их появлению предшествовали огромные достижения в ядерной физике, которые связаны с масштабными работами по созданию ядерного оружия. В рамках этих исследований созданы атомные реакторы, линейные ускорители, бетатроны, циклотроны, тандем-генераторы и другие ускорители элементарных частиц. При бомбардировке исследуемых материалов частицами происходят ядерные реакции, которые можно использовать для получения уникальных аналитических сигналов. Наиболее распространенный нейтронно-активационный анализ - впервые проведен в США в 1936 году для исследования смеси редкоземельных элементов. В дальнейшем радиоаналитические методы интенсивно развивались в странах, обладающих соответствующими источниками - США, СССР, Франция, Германия, Англия. Прогресс продолжался до Чернобыльской аварии, после которой кардинально изменились требования к радиационной безопасности. Исследования радиоаналитических методов резко сократились, а сами они применяются в исключительных случаях.

Итак, за прошедшее столетие сформировались инструментальные методы неорганического анализа - атомно- спектральные, рентгеновские, масс-спектральные и радиоаналитические, которые в принципе пригодны для решения задач по анализу редких, редкоземельных, благородных металлов и материалов на их основе. Однако для реализации этих возможностей необходима разработка специальных методик анализа применительно к конкретным объектам.

На стадии разработки методик анализа возникла новая научно-техническая дисциплина, которую называют химической метрологией или аналитическими измерениями. Дело в том, что химический анализ - специфический вид измерений, при котором аналитический сигнал сравнивается с некоторой реперной величиной, играющей роль эталона. Но, в отличие от других основных физических величин, в метрологии единица количества вещества моль - не имеет своего материального эталона. Поэтому для решения метрологической задачи нужны компромиссные подходы - использование чистых веществ в качестве индивидуальных молей, применение так называемых первичных методов и др. Кроме того, аналитический сигнал зависит от состава пробы и множества других помехинструментальных и методических. В результате с учетом этих и других особенностей химического анализа как вида измерений сформировался специальный раздел аналитической химии - химическая метрология. Метрологические характеристики: точность, правильность, прецизионность, воспроизводимость, пределы обнаружения и определения и др. - стали главными критериями пригодности аналитической методики для исследования конкретного объекта.

В 1960 году вышла в свет монография выдающегося русского ученого математика В. В. Налимова «Применение математической статистики при анализе вещества", которая переведена на разные языки. Она стала настольной книгой многих творческих аналитиков и фундаментальной основой метрологии химического анализа. Затем появилось много аналитиков-метрологов, опубликованы десятки монографий, выпущены отечественные и международные стандарты на методы аналитических измерений. И, главное, метрологический раздел стал неотъемлемой частью любой методики количественного анализа.

Итак, к 60-м годам прошлого столетия сформировался базис для полноценного аналитического контроля практически всех видов веществ и материалов на основе редких и благородных металлов - атомно-спектральные, рентгеноспектральные, масс-спектральные, радиоаналитические методы и их приборное оснащение, а также метрологическое сопровождение.

Практика показала, что полный анализ веществ и материалов на основе редких и благородных металлов можно выполнить только на основе комбинирования взаимодополняющих методов и методик анализа, их метрологического обеспечения и высококвалифицированного персонала. На 


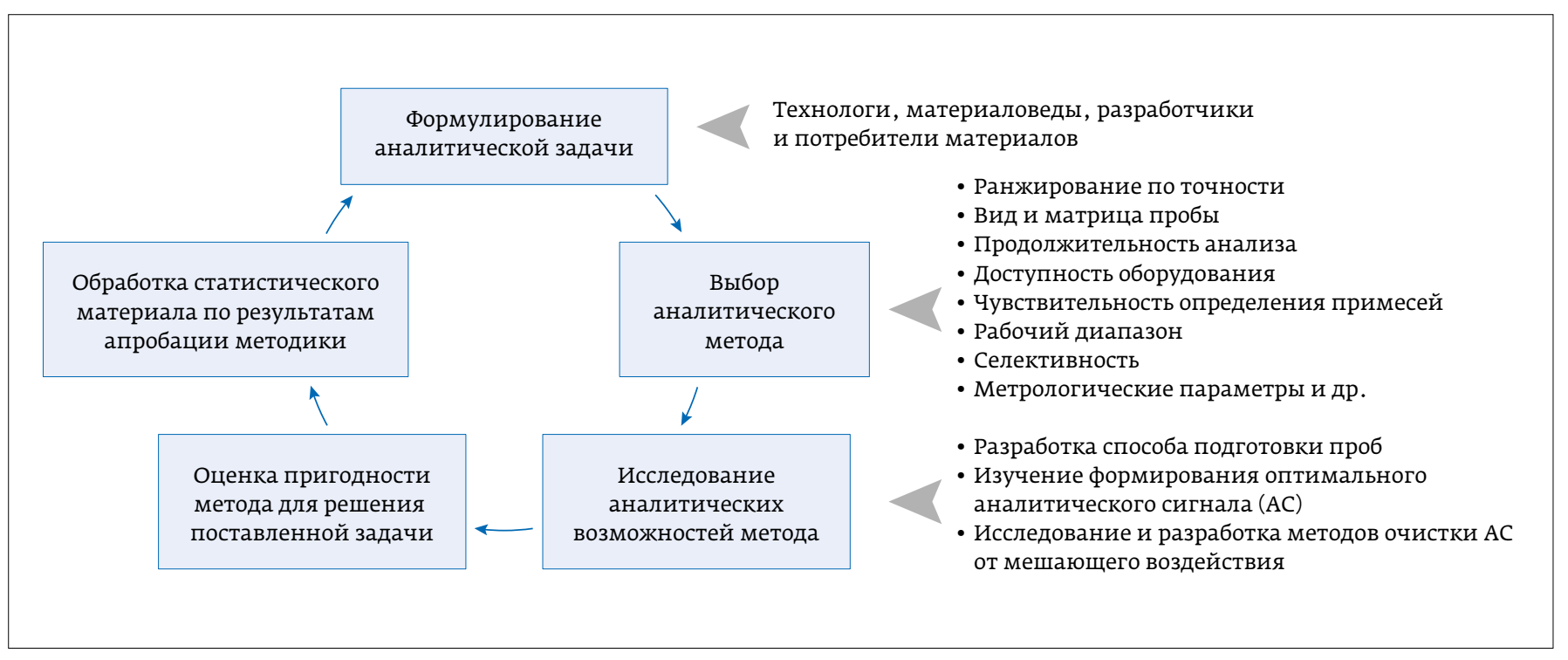

Научно-исследовательские этапы при разработке методики анализа

этой основе в промышленно развитых странах созданы специализированные аналитические лаборатории.

Примером такой лаборатории в России может служить аналитико-сертификационный центр института Гиредмет, имеющий международное признание и заслуги. Оснащение центра включает аналитические приборы, среди которых можно отметить уникальный набор масс-спектрометров с искровым источником ионов JMSO1B2, JEOL (Япония), тлеющим разрядом Finnigan ELEMENT GD (Германия) и индуктивно связанной плазмой Х-7 (Thermo Electron Corp., США); атомно-абсорбционный спектрометр с непрерывным источником спектра contrAA 600 (Analytik Jena, Йена, Германия); комплект оборудования для определения газообразующих примесей методом газовой экстракции LECO и др. Вспомогательное оборудование (лабораторный гидравлический пресс CARVER (CARVER, США), микроволновая система MARS-5 (CEM, США), аналитическая просеивающая машина AS200 control (Retsch, Германия), планетарная шаровая мельница RS200 (Retsch, Германия), вибрационная дисковая мельница RS200 (Retsch, Германия), анализатор влажности MRS120-3 (Kern \& Sohn, Германия)) предназначено в первую очередь для пробоподготовки, которая необходима для функционирования аналитических приборов и реализации методик.

На сегодняшний момент, в целом, существующая в мире приборная база и методологическое сопровождение вполне способны обеспечить аналитическим контролем практически все виды редкометаллической продукции при условии проведения дополнительных методических исследований применительно к конкретным объектам.

Но наука и технология продолжают интенсивно развиваться и предъявлять новые требования к составу материалов и, соответственно, к методам анализа.
Одно из главных направлений современного развития аналитических методов связано с микроэлектроникой и нанотехнологиями. Сегодня идет процесс становления нового раздела аналитической химии, объединяющего методы локального анализа, анализа поверхности, наноанализа. Для решения этой сложнейшей проблемы уже создано более 70 методов с соответствующим приборным обеспечением.

Основные методы аналитической нанодиагностики можно разделить по признаку первичной генерации аналитического сигнала при помощи пучков электромагнитного излучения или потока частиц (электронов, протонов и т.д.). Каждый зонд имеет свою рациональную область работы и требует применения сложных и дорогостоящих приборов. Для практического использования методов необходимы разработки специальных методик анализа, наибольшие трудности связаны с отсутствием образцов сравнения или эталонов. Из-за высокой стоимости в мире не существует реальных лабораторий, владеющих всеми методами нанодиагностики. Поэтому обычно для исследования выбираются один или несколько подходящих методов по принципу минимальной достаточности.

Следующая проблема - это установление формы нахождения элемента одновременно с его элементным определением. Такие методы и приборы сейчас появились и продолжают развиваться, например, сочетающие рентгеновскую флуоресценцию с дифрактометрией.

Популярны методы изотопного анализа, обусловленные появлением эффективных способов разделения изотопов (а большинство редких элементов - полиизотопные) и расширением их практического применения. В этой области не имеет конкурентов и наиболее перспективна массспектрометрия. 
Кратко остановимся на особенностях развития методов анализа благородных металлов, поскольку они во многом сходны с редкими металлами. Однако благородные металлы (золото, серебро и металлы платиновой группы - платина, палладий, родий, иридий, рутений и осмий) отличаются не только уникальными физико-химическими свойствами, но относятся также к категории драгоценных или валютных металлов.

По этой причине они всегда находятся в сфере особого внимания государства, их производство, анализ и хранение регламентируются законодательством, международная торговля проходит на специальных биржах по определенным правилам и требованиям к химической чистоте.

До 1915 года 90\% мировой добычи платины приходилось на Россию. Однако шлиховый металл вывозили за границу, он поступал в руки иностранных компаний, которые проводили аффинаж и изготовление продукции. В середине 19 века российский ученый Карл Клаус открыл новый элемент платиновой группы и назвал его в честь России рутением. В 1917 году в Екатеринбурге был построен платиновый аффинажный завод, который недавно отметил свое 100-летие.

Сразу после Октябрьской революции при Академии наук в Петрограде был учрежден Институт по изучению платины и других благородных металлов. Первым его директором был Л. А. Чугаев, а с 1922 года - академик Н. С. Курнаков. В 1937 году этот институт, а также Институт физико-химического анализа и физико-химический отдел Лаборатории высоких давлений в Ленинграде объединили в Институт общей и неорганической химии (ИОНХ) под руководством академика Н.С. Курнакова. Исследования ученых ИОНХ и специалистов завода по обработке цветных металлов в Екатеринбурге легли в основу российской технологии аффинажа платиновых металлов.

Многие годы, вплоть до распада в 1990 году Советского Союза, ИОНХ в составе научных школ академиков И. М. Черняева, И. В. Тананаева, Ю. А. Золотова обеспечивал научное сопровождение отечественной платиновой промышленности в Норильске, Красноярске, Екатеринбурге. Особое внимание уделялось аналитическому контролю от минерального сырья до получения всех шести высокочистых платиновых металлов и их сплавов высшего мирового качества.

Возвращаясь к теме аналитического обеспечения промышленности драгоценных металлов, отметим следующее. Выше упоминалось, что, в отличие от редких металлов, драгоценные металлы продают через международные валютные биржи, в первую очередь Лондонскую ассоциацию благородных металлов при Лондонской бирже. Для этого специально разработан стандарт качества и требования к его аналитическому сопровождению.

Компаниям, выполнившим эти требования, вручается специальный сертификат "Гуд Деливери" (качественная поставка), который гарантирует получение максимальной выручки за реализованную продукцию. Такая ситуация стимулирует разработку и использование современных высокоэффективных методов анализа. Большинство аффинажных заводов, в том числе и в России, обеспечено современным аналитическим оборудованием, участвует в международных сличениях и имеет сертификат "Гуд Деливери".

Состояние аналитической химии металлов платиновой группы детально охарактеризовано в фундаментальной монографии под редакцией академика Ю. А. Золотова,

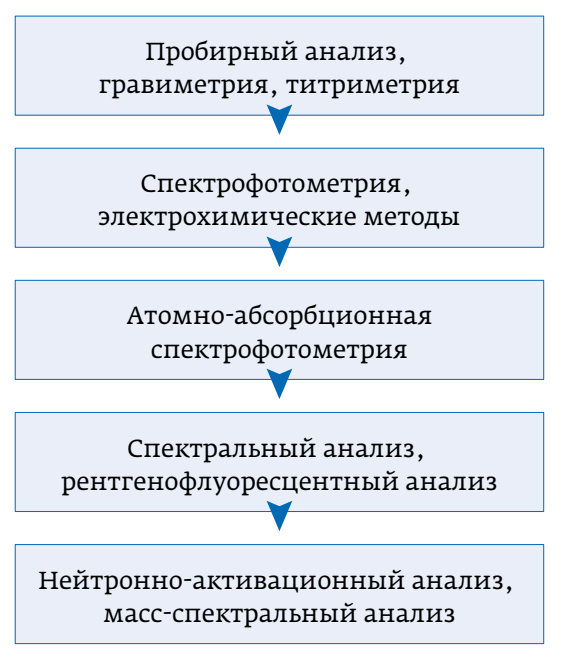

В середине 20 века данные методы были наиболее распространенными и универсальными в работе аналитических лабораторий.

Основными объектами анализа данным методом являлись руды и концентраты

Высокая чувствительность, экспрессность, широкий интервал определяемых содержаний от (сотых долей до десятков процентов), простота аппаратуры

Конец 60-х годов ознаменовался активным развитием работ по атомно-абсорбционной спектрофотометрии

Спектральный анализ использовался для определения драгоценных металлов в различных материалах: чистых металлах, сплавах, шламах, рудах 
вышедшей в 2003 году. В настоящий момент под эгидой ИОНХ РАН и Научного совета по аналитической химии РАН готовится издание новой монографии по химическому анализу благородных металлов.

Пути дальнейшего развития методов анализа благородных металлов и редких элементов несколько отличаются. При анализе драгоценных металлов основная цель - не в достижении экстремальных аналитических характеристик, а в создании простых и надежных методов анализа минерального и вторичного сырья, ювелирных сплавов, изделий из благородных металлов, различного рода сплавов и покрытий, а также общих подходов к пробоотбору и пробоподготовке к анализу. $\because *$

В заключение отметим, что редкие и благородные металлы входят в число самых перспективных объектов материаловедения. Их применение в науке, технике и повседневной жизни зависит от триады: состав - строение - свойства. Исследование этой триады осуществляется в соответствии с учением академика Н. С. Курнакова о физико-химическом анализе. Первичное звено в исследованиях - химический состав, который определяется многочисленными методами аналитической химии. В этой области есть много достижений, но еще больше проблем, которые пока остаются нерешенными. Их решение требует больших усилий, средств и времени, но ожидаемый результат обнадеживает и вдохновляет.

\section{ЖИДКОКРИСТАЛЛИЧЕСКИЕ ЭЛАСТОМЕРЫ МЕНЯЮТ ФОРМУ ПРИ НАГРЕВАНИИ}

жидкокристаллические эластомеры представляют собой полимерную сеть с включениями жидких кристаллов. Они обратимо меняют форму в ответ на нагревание, воздействие ультрафиолетового и инфракрасного света, магнитных и электрических полей. Их используют в робототехнике и медицине, где необходимы материалы, принимающие заданную форму при определенных условиях. При формовке поверхность материала испытывает напряжения разной силы и направлений. Чем сложнее форма, тем больший диапазон
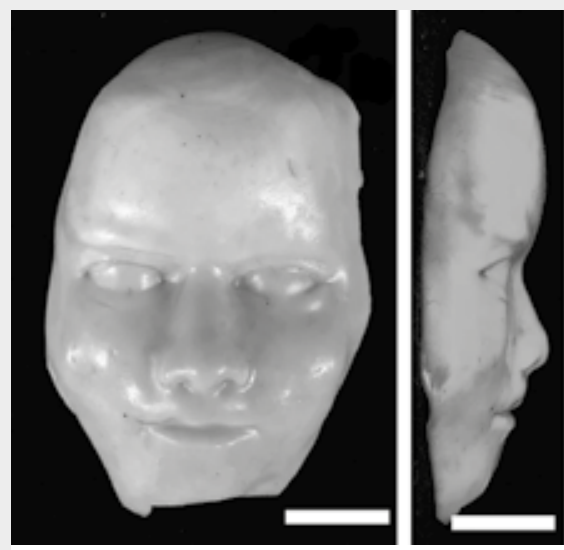

Температура меньше температуры перехода нематик-изотропик (формы эластомера) деформаций должен "запомнить" жидкокристаллический эластомер, чтобы обратимо трансформироваться. Эта проблема тормозила использование жидкокристаллических эластомеров.

Ученые Института Райса (США) предложили метод двухстадийной тиол-акрилатной полимеризации для синтеза эластомера с памя тью на различные механические воздействия. На первой стадии жидкокристаллический акрилат (мономер) растворяли в хлороформе при $70{ }^{\circ} \mathrm{C}$, остужали до комнатной температуры, добавляли
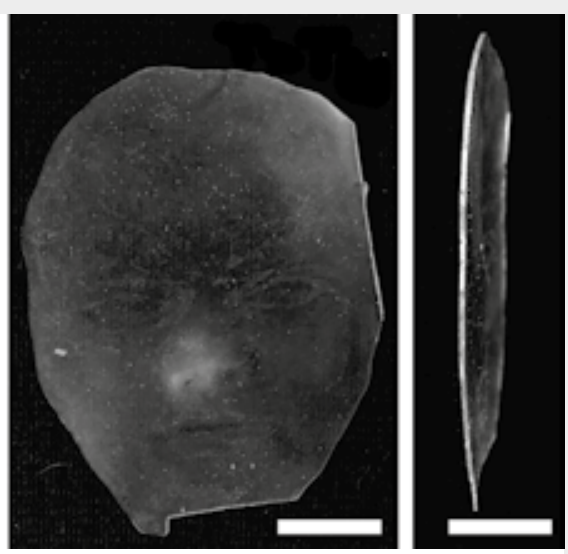

Температура больше температуры перехода нематик-изотропик (формы эластомера) пентаэритритолтетракис меркаптопропионат (сшивка) и (этилендиокси)диэтантиол (удлинитель цепи) и помещали в форму на 5 ч. Таким образом задавали плоскую форму эластомера. На второй стадии программировали интересующую форму материала: нагревали до $80^{\circ} \mathrm{C}$ для удаления хлороформа, снова формовали и облучали ультрафиолетом. Авторы подобрали соотношение мономера и сшивки, при котором эластомер удерживал заданную форму и обратимо трансформировался в плоский лист при нагревании. Методами скручивания, растягивания, выдавливания и печати из листов эластомера формовали розу, маску человека, логотип, деталь детского конструктора.

Материал можно применять для изготовления мягких роботов, имитирующих живой организм, биомедицинских материалов, которые принимают нужную форму при температуре тела, тактильных кнопок для слабовидящих.

Soft Matter, 2018. DOI: $10.1039 / C 8 S M 02174 K$ 